\title{
Análise funcionalista do caso Ablativo na língua armênia ocidental
}

DOI: http://dx.doi.org/10.21165/el.v50i2.2929

\author{
Deize Crespim Pereira' \\ Sarkis Ampar Sarkissian²
}

\section{Resumo}

Este trabalho tem por objetivo analisar os usos e funções do caso Ablativo na variedade linguística ocidental do idioma armênio. O corpus se constitui de ocorrências coletadas em jornais digitais armênios, publicados na Armênia e na diáspora. A análise é qualitativa e baseada em pressupostos teóricos da Gramática Funcional de Dik (1997) e da Gramática Sistêmico-Funcional de Halliday (1994; HALLIDAY; MATTHIESSEN, 2014). Procuramos identificar as funções semânticas e sintáticas do substantivo marcado com morfologia de Ablativo. Partimos inicialmente da hipótese de que os diversos usos empiricamente constatados do caso Ablativo podem ser explicados como funções ou sentidos inter-relacionados, associados a um morfema, e de que tais sentidos poderiam ser generalizados em termos da categoria conceptual de "origem".

Palavras-chave: caso Ablativo; língua armênia ocidental; Linguística Funcional.

1 Universidade de São Paulo (USP), São Paulo, São Paulo, Brasil; deize.pereira@usp.br; https://orcid.org/0000-0001-8157-3000

2 Universidade de São Paulo (USP), São Paulo, São Paulo, Brasil; sarkis@usp.br; https://orcid.org/0000-0003-1167-5946 


\title{
Functional analysis of the Ablative case in Western Armenian language
}

\begin{abstract}
This paper aims to analyze the uses and functions of the Ablative case in the Western Armenian language. The data were collected from Armenian digital journals, published in Armenia and the Armenian Diaspora. The analysis is qualitative and based on theoretical tools of Dik's Functional Grammar (1997), and Halliday's Systemic-Functional Grammar (1994; HALLIDAY; MATTHIESSEN, 2014). We seek to identify the semantic and syntactic functions of the noun marked with the Ablative case. We start from the hypothesis that the different uses of the Ablative case could be explained as interrelated functions or meanings, associated with a particular morpheme and that these meanings could be generalized in terms of the conceptual category of "origin".
\end{abstract}

Keywords: Ablative Case; Western Armenian language; Functional Linguistics.

\section{Introdução}

Este trabalho tem por objetivo uma análise qualitativa dos usos do caso Ablativo na variedade linguística ocidental do armênio, sob uma perspectiva funcionalista. O corpus se constitui de ocorrências coletadas de textos publicados em doze veículos de comunicação digitais da Armênia e da diáspora ocidental. Os pressupostos teórico-metodológicos são retirados da Gramática Funcional de Dik (1997) e da Gramática Sistêmico-Funcional de Halliday (1994; HALLIDAY; MATTHIESSEN, 2014).

O artigo está dividido em três seções. A primeira consiste de revisão da literatura linguística, mais especificamente, uma análise crítica de gramáticas descritivas e de livros didáticos de armênio ocidental, mostrando como estes apresentam o caso Ablativo. Na segunda seção, fazemos uma breve apresentação dos pressupostos teóricos e metodológicos da Linguística Funcional que norteiam o presente estudo. A terceira seção contém nossa análise qualitativa do corpus de armênio ocidental, com base nos pressupostos funcionalistas.

\section{0 caso ablativo na literatura linguística}

Analisamos como se define e se exemplifica o caso Ablativo nas gramáticas descritivas de Riggs (1856), Gulian (1902), Feydit (1935), Kogian (1949), Kerouzian (inédito) e Ekizian 
(2004)3 , e nos livros didáticos de Bardakjian e Thomson (1992), Sakayan (2000, 2012) e Hagopian (2005).

Um problema recorrente nas gramáticas (RIGGS, 1856; GULIAN, 1902) é limitar-se a explicitar a morfologia do Ablativo, seja de nomes, com exemplos do tipo npnh-ț / vorti-en/ 'from the son', em que /e/ corresponde à desinência de Ablativo, e /n/ ao artigo definido; seja de pronomes, que também são declináveis no armênio, como em ưtuqut / mezme / 'from us' (GULIAN, 1902). Os exemplos citados são de substantivos isolados e descontextualizados, ou de pequenas frases. Por tais exemplos, a impressão que se tem é de que o Ablativo rege apenas elementos no interior de sintagmas adverbiais.

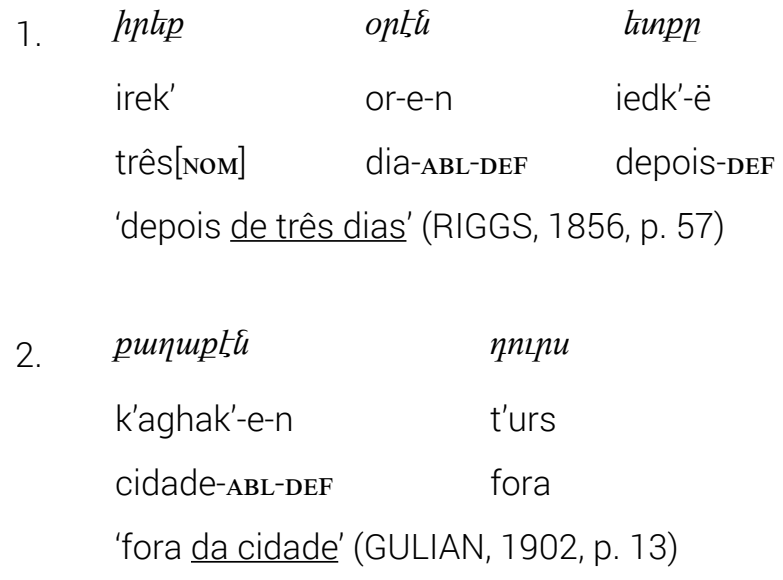

Muitas gramáticas definem o Ablativo por meio de preposições, estabelecendo paralelos entre o armênio e línguas como o francês, português e inglês. Assim, segundo Kogian (1949), a relação "de" (from) é expressa pelo caso Ablativo. Gulian (1902), da mesma forma, explica que, para identificar o caso Ablativo numa sentença, deve-se perguntar "from whom?", "from which?". O mesmo autor afirma que, na voz passiva, a preposição by (por) se traduz em armênio pelo caso Ablativo (GULIAN, 1902), ex.:
Fnjūn
2hânıliguı

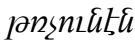
P'uyn-ë
chin-v-ets'-av
t'(ë)rtch'un-e-n
Ninho[NOM]-DEF
construir-PASS-IND.AOR-3SG
pássarO-ABL-DEF
'O ninho foi construído pelo pássaro.' (GULIAN, 1902, p. 72)

\begin{abstract}
30 uso de gramáticas antigas se justifica pela dificuldade de se encontrar gramáticas de edição atual sobre o armênio ocidental, variedade linguística moderna que atualmente está perdendo sua vitalidade, devido à redução de seu número de falantes. Das gramáticas e livros didáticos foram retirados somente os exemplos em armênio. A glosa e tradução são de nossa responsabilidade. Para reproduzir a pronúncia, optamos por uma transliteração em letras latinas, voltada para falantes do português.
\end{abstract}


Dentre as gramáticas consultadas, Feydit (1935) e Kogian (1949) são os únicos autores que chegam mais próximos de uma definição do caso Ablativo em termos de suas funções. Na parte dedicada ao substantivo e suas declinações, Feydit enumera o "valor dos casos da declinação". Segundo ele, o Ablativo pode indicar:

a) a origem ou ponto de partida, exemplo:

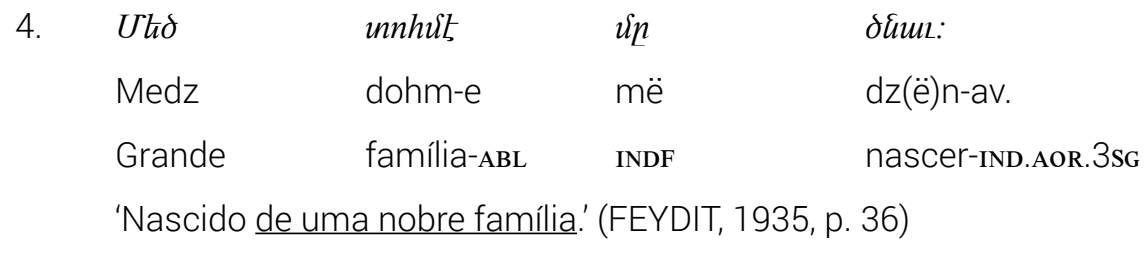

b) o termo de comparação, exemplo:

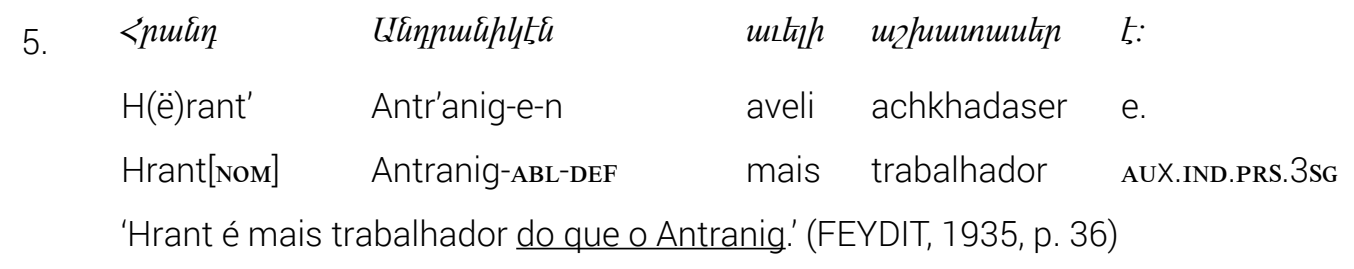

c) "o sujeito do verbo passivo [sic] que sustenta a ação" (FEYDIT, 1935, p. 36, tradução nossa ${ }^{4}$ ). Note-se que a explicação para o uso do Ablativo na voz passiva demonstra-se bastante confusa, já que o elemento que recebe caso Ablativo é o Agente da ação e não o sujeito sintático da sentença, como o autor afirma; exemplo:

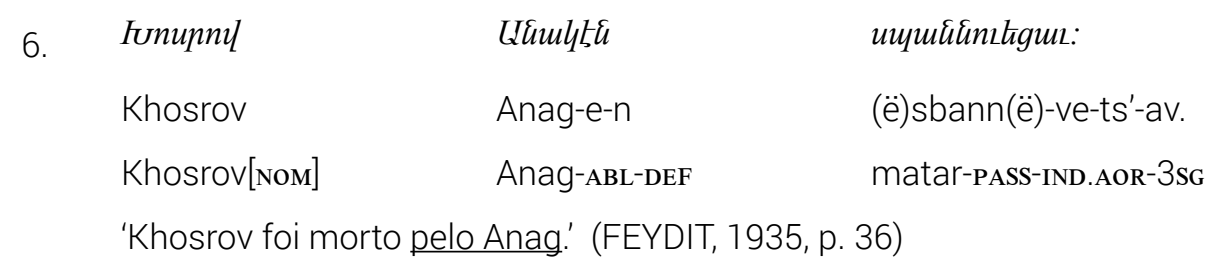

4 No original: "il indique celui dont le sujet du verbe (passif) supporte l'action". 
d) a causa, sendo esta entendida como a origem da ação ou do estado, exemplo:

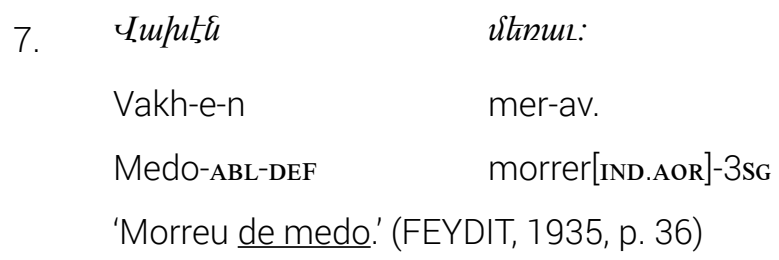

e) o sentido "dentre" em expressões partitivas, exemplo:

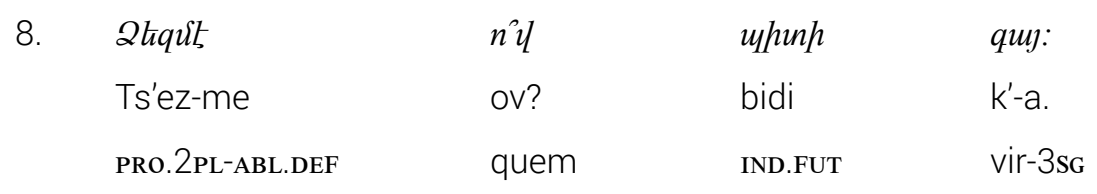

'Quem dentre vós virá?' (FEYDIT, 1935, p. 36)

No capítulo referente aos complementos circunstanciais, o autor afirma que o Ablativo "serve" ainda para:

f) responder as questões "desde quando?", "desde quanto tempo?", exemplo:
9. EnLไnццй
ulukum:
lereg-vëne
(ë)sg(ë)sial.
Ontem-ABL
inicial
'Desde ontem.' (FEYDIT, 1935, p. 43)

g) para indicar o período de tempo previsto para executar uma ação no futuro, como no exemplo (10). Comparando esta categoria com (f), vemos que o autor considera relevante a localização do tempo discriminado pelo elemento no Ablativo: do passado ao presente (exemplo 9) x período no futuro (exemplo 10):

10.

\begin{tabular}{|c|c|c|c|}
\hline$U b_{4}$ & muihus $\tilde{a}$ & $4 n$ & 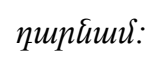 \\
\hline Meg & amis-e-n & gë & t'arn-am. \\
\hline Um & mêS-ABL-DEF & IND.PRS & voltar- $1 \mathrm{sG}$ \\
\hline
\end{tabular}


h) o lugar de onde vem alguém ou algo, como no exemplo a seguir. Observe-se que Feydit (1935) faz uma distinção entre este tipo e a categoria (a) origem, mencionada anteriormente, levando em conta o fato de que o tipo (h) envolve procedência ou origem especificamente do ponto de vista do espaço (origem em um lugar no espaço).

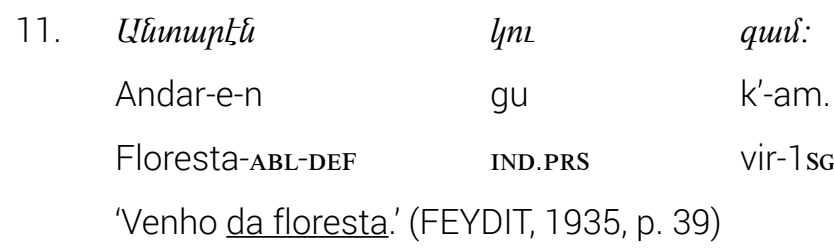

i) o lugar por onde se passa, exemplo:

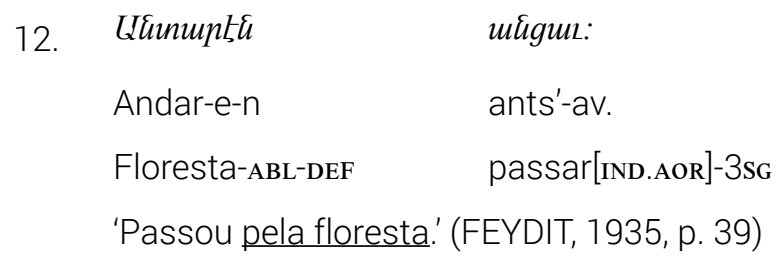

j) o complemento de material (o autor não faz menção ao fato de que, neste caso, trata-se de complemento ou, mais propriamente, adjunto do nome e não do verbo, e, portanto, um emprego distinto dos "complementos circunstancias" citados acima), exemplo:

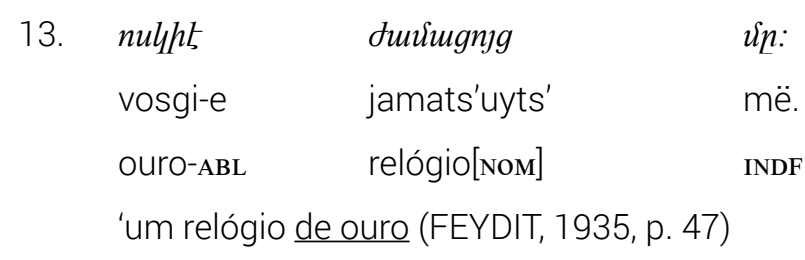

Ekizian (2004) também define o Ablativo como um complemento circunstancial, que pode indicar procedência, origem ou causa, como respectivamente ilustram os exemplos a seguir. Note-se que, ao contrário do que Ezikian afirma, nos exemplos (14-15), o Ablativo não constitui um complemento circunstancial, mas sim um "complemento oblíquo", o chamado "quase argumento" pelas gramáticas do português (CASTILHO, 2010).

\begin{tabular}{|c|c|}
\hline คunhqt\& & $4 n$ \\
\hline P'ariz-e-n & gu \\
\hline Paris-ABL-DEF & IND.PRS \\
\hline
\end{tabular}

'Venho de Paris.' (EKIZIAN, 2004, p. 31) 
15.

\begin{tabular}{|c|c|c|}
\hline Чшишри & 4upts & $4 n$ \\
\hline Garak'-ë & gat'-e-n & gë \\
\hline Manteiga[ACC]-DEF & leite-ABL-DEF & IND.PRS \\
\hline
\end{tabular}

'Do leite tiram a manteiga.' (EKIZIAN, 2004, p. 31)

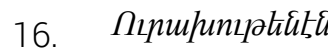

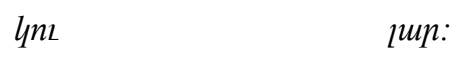

Urakhut'-ene-n gu l-ar.

Felicidade-ABL-DEF IND.PRET.IMPERF chorar-3SG

'Chorava de felicidade.' (EKIZIAN, 2004, p. 31)

Um exemplo semelhante é citado por Kogian (1949), no qual o constituinte da sentença no caso Ablativo tem indiscutivelmente papel argumental:

\begin{tabular}{|c|c|}
\hline ququakatht & ұиһикмџ: \\
\hline K'azan-ner-e & vakhna-l. \\
\hline Fera-PL-ABL & temer-INF \\
\hline
\end{tabular}

Kogian (1949), na parte de sua gramática denominada Sintaxe, faz uma descrição detalhada do Ablativo por meio de suas funções e contextos de uso. Segundo ele, o Ablativo pode ser utilizado com os sentidos de: (i) separação, (ii) fonte, origem e material (como nos contextos a, h e j de FEYDIT, 1935, enumerados acima), (iii) causa (como na categoria d de FEYDIT, 1935), (iv) Agente com verbo passivo (categoria c), (v) duração (contextos f e g), (vi) comparação (contexto b), (vii) partitivo (categoria e). Todos estes contextos são, portanto, contemplados por Feydit, com exceção do primeiro. Inversamente, apenas na gramática de Feydit aparece o contexto de Ablativo designando o lugar por onde se passa (exemplo 12).

A categoria (i), o chamado Ablativo de separação ou privação, só aparece em Kogian (1949). Vejamos os exemplos citados pelo autor. O sentido de separação nos parece mais evidente no primeiro exemplo. Note-se que, em todos estes contextos, o Ablativo constitui argumento do verbo.

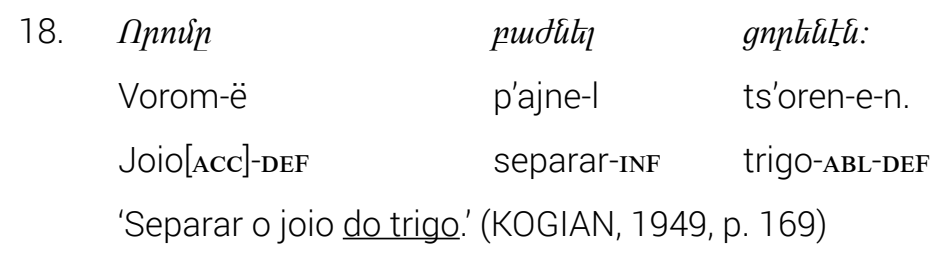


19. Чицидь๘

unduj:

Argadz-e-n

ardz-a.

Desastre-ABL-DEF

escapar[IND.AOR]-1 SG

'Escapei do desastre.' (KOGIAN, 1949, p. 169)

20. fuuntú

ұимими:

P'and-e-n

p'akh-an.

Prisão-ABL-DEF

fugir[IND.AOR]-3PL

'Fugiram da prisão.' (KOGIAN, 1949, p. 169)

Kogian (1949) menciona também o uso de Ablativo com função atributiva, atuando como adjunto ou complemento de nome ou adjetivo. O exemplo (22) constitui um emprego especial em que uma parte do corpo é colocada no caso Ablativo para atribuir uma qualidade a uma pessoa.

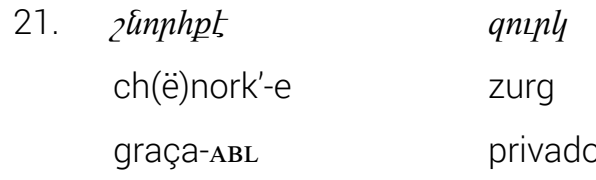

'Privado de graça.' (KOGIAN, 1949, p. 173)

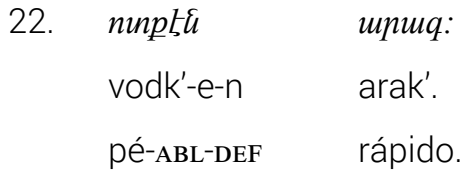

'rápido de pé'; 'veloz' (KOGIAN, 1949, p. 173)

O autor ainda trata de preposições (como no exemplo a seguir) e advérbios usados como posposições (como nos exemplos 1 e 2, citados anteriormente), que pedem caso Ablativo, ilustrando seu emprego com frases e sentenças completas.

23

\begin{tabular}{|c|c|c|c|}
\hline fwgh & ujnknte & цuјhน & Emktr \\
\hline P'ats'i & ayr-er-e-n & g-ayin & naiev \\
\hline Além de & homem-PL-ABL-DEF & haver[IND.PRET.IMPERF]-3PL & também \\
\hline
\end{tabular}


Kerouzian (inédito) atribui ao caso Ablativo a função de expressar o complemento indireto circunstancial de saída, partida, chegada, caída de um lugar, procedência e comparação. Este autor não cita sentenças completas e mistura contextos de uso que nos parecem semanticamente distintos, como nos exemplos a seguir: enquanto o complemento de cair parece mais um complemento verbal de origem (cair de), o de olhar está mais relacionado a percurso ou trajeto do olhar.

\begin{tabular}{|c|c|c|}
\hline 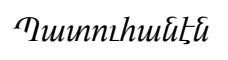 & häluz & (Emјkgmz) \\
\hline Baduhan-e-n & ing-av & (nay-ets'-av) \\
\hline Janela-ABL-DEF & cair[IND.AOR]-3sG & (olhar-IND.AOR-3sG) \\
\hline
\end{tabular}

Até aqui vimos como é tratado o caso Ablativo em gramáticas da língua armênia ocidental. Cabe, por fim, uma observação com relação aos livros didáticos consultados. Bardakjian e Thomson (1992) se limitam a uma definição semântica bem abrangente de Ablativo, o qual designa, segundo eles, o lugar onde se inicia um movimento ou do qual algo é retirado. Hagopian (2005) é uma das poucas obras consultadas que define o Ablativo basicamente em termos sintáticos, destacando seu uso como um argumento pleno do verbo (como no exemplo 25), adjunto adverbial de lugar ou de tempo (exemplo 10), e atributivo de nome (como no exemplo 13).

\begin{tabular}{|c|c|c|c|c|}
\hline Emntê & anıbn & $4 n$ & итпш๕щщ & LрппицLE: \\
\hline Nare-n & $\mathrm{n}(\ddot{\mathrm{e}}) \mathrm{ver}$ & gë & (ë)sdan-a & Ardag-e-n. \\
\hline Narê[Nom]-DEF & presente[ACc] & IND.PRS & receber-3ss & Ardag-ABL-DEF \\
\hline
\end{tabular}

Sakayan $(2000,2012)$ é o livro didático que descreve mais detalhadamente o caso Ablativo. A autora destaca os vários papéis sintáticos que pode exercer, enfatizando a diferença argumento $x$ adjunto (embora sem utilizar estes termos), em boa parte ignorada por outras obras. Assim, a autora esclarece que enquanto em determinados contextos o Ablativo é um elemento circunstancial, em outros é complemento exigido pelo verbo (exemplo 17), ou pelo núcleo do sintagma adjetival (exemplo 21) ou adverbial (exemplo 2).

\section{Pressupostos teóricos e metodológicos}

Para analisar o caso Ablativo no armênio ocidental, adotamos pressupostos da Linguística Funcional, mais especificamente, da Gramática Funcional de Dik (1997) e da Gramática Sistêmico-Funcional de Halliday (1994; HALLIDAY; MATTHIESSEN, 2014). 
Passemos, pois, aos conceitos teóricos relevantes para nosso estudo. Dik (1997) entende caso como diferenças sistemáticas na forma dos predicados nominal e adjetival, isto é, distinções morfológicas que correspondem a diferenças funcionais dos termos que modificam. Os casos mais comuns, encontrados em diferentes línguas, são enumerados no quadro 1, junto de suas funções mais básicas e primárias.

Segundo Dik (1997, p. 369), a distinção de caso serve a dois propósitos: (i) função de caracterizar: os casos caracterizam um termo como tendo um conjunto limitado de possíveis funções semânticas e sintáticas; e (ii) função de distinguir: os casos servem para diferenciar as funções semânticas e sintáticas dos termos na estrutura da oração.

O autor nota que a função principal dos casos é expressar funções semânticas subjacentes, mas que em alguns contextos os casos servem para manifestar funções sintáticas, como evidenciado no quadro 1, que realmente mistura ambas as definições. Apesar de propor este quadro, Dik defende que não é possível identificar um sentido comum a todos os usos de determinado caso, justamente pelo fato de um caso poder expressar mais de uma função.

Quadro 1. Funções primárias dos casos gramaticais

\begin{tabular}{|c|c|c|}
\hline Línguas & Caso & Função primária \\
\hline \multirow{4}{*}{ Nominativas } & Nominativo & Primeiro argumento; Sujeito \\
\cline { 2 - 3 } & Acusativo & Segundo argumento, Paciente, Objeto \\
\hline \multirow{4}{*}{ Ergativas } & Absolutivo & Sujeito de verbo intransitivo; Objeto de verbo transitivo \\
\cline { 2 - 3 } & Ergativo & Sujeito de verbo transitivo \\
\hline \multirow{4}{*}{ Todas as línguas } & Genitivo & Possuidor (relação entre termos) \\
\cline { 2 - 3 } & Dativo & Recipiente \\
\cline { 2 - 3 } & Instrumental & Instrumento \\
\cline { 2 - 3 } & Partitivo & Relação parte-todo \\
\cline { 2 - 3 } & Locativo & Localização \\
\cline { 2 - 3 } & Ablativo & Origem \\
\cline { 2 - 3 } & Alativo & Direção \\
\hline
\end{tabular}

Fonte: Dik (1997, p. 369)

Termos, na Gramática Funcional de Dik (1997), são expressões usadas para referir a entidades. O Genitivo estabelece uma relação entre termos (possuidor e possuído). Já outros casos são definidos como argumentos do verbo (sujeito, objeto), estabelecendo, portanto, uma relação entre o verbo e seus argumentos. Os argumentos se definem como termos requeridos pelo predicado para formar uma predicação nuclear completa, 
ao contrário dos satélites (termos acessórios, adjuntos, que proporcionam informação adicional, circunstancial); exemplos:

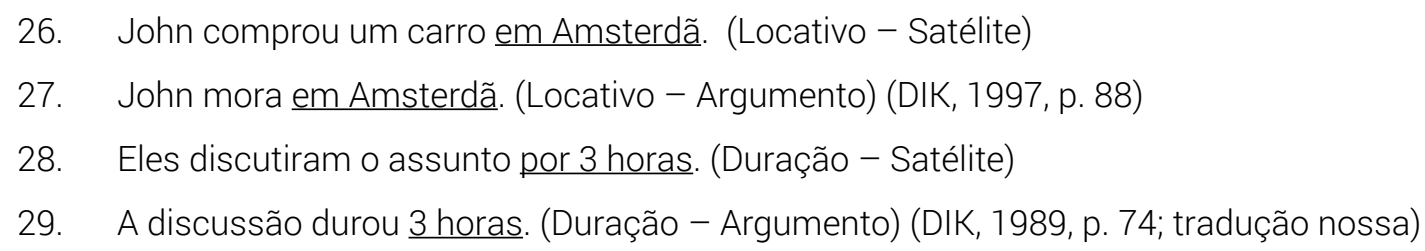

Utilizando o latim como língua de ilustração, o autor nota que: (i) nos predicados de uma posição argumental (um só argumento), este é realizado com caso Nominativo (e/ ou como sujeito) em 100\% dos casos; (ii) o segundo argumento de predicados de três posições argumentais é categoricamente expresso com caso Acusativo, ao passo que se o predicado tiver duas posições argumentais, o segundo argumento geralmente também é um Acusativo; (iii) o Dativo e o Ablativo juntos respondem por 96,9\% dos casos de terceiro argumento.

Da teoria de Dik, interessa-nos sobretudo propor uma análise do Ablativo que contemple suas funções semânticas e sintáticas. As funções semânticas especificam o papel dos referentes dos termos no estado de coisas designado pela predicação na qual estes termos ocorrem (exs.: Agente, Paciente, Recipiente, etc.), e as funções sintáticas especificam o ponto de vista através do qual um estado de coisas é apresentado (exs.: sujeito e objeto).

As designações primeiro, segundo e terceiro argumento não têm relação com a ordem com que estes aparecem na sentença. Considerando a função semântica, Dik postula que argumentos Agentes são mais centrais do que Pacientes, e Pacientes são, por seu turno, mais centrais do que Recipientes. É com base nisto que o autor faz uma distinção entre: primeiro argumento (como Agente), segundo argumento (como Paciente) e terceiro argumento (como Recipiente). O quadro a seguir mostra a relação estabelecida por Dik (1997) entre argumentos e suas funções semânticas.

Quadro 2. Funções semânticas e posições argumentais

\begin{tabular}{|l|l|l|}
\hline [1] & [2a] & [2b] \\
\hline Agente & Paciente & Recipiente [Experienciador] \\
Posicionador & [Experienciador] & Locativo \\
Força & & Direção \\
Processado [Experienciador] & & Origem \\
Zero [Experienciador] & & Referência \\
\hline
\end{tabular}

Fonte: $\operatorname{Dik}(1997$, p. 120) 
O autor explica que, em qualquer estrutura de predicado, o primeiro argumento terá uma das funções listadas em (1); se a estrutura do predicado tiver dois lugares, o segundo argumento terá uma das funções listadas em (2a) e (2b); se tiver três lugares, o segundo argumento terá a função de Paciente, e o terceiro argumento terá uma das funções enumeradas em (2b).

Dik também propõe uma hierarquia de possíveis funções semânticas para sujeito e objeto, como descrito a seguir.

Quadro 3. Hierarquia de funções semânticas

\begin{tabular}{|c|c|c|c|c|c|c|c|c|c|c|c|c|c|}
\hline \multicolumn{14}{|c|}{ Agente $>$ Paciente $>$ Recipiente $>$ Beneficiário $>$ Instrumento $>$ Locativo $>$ Tempo } \\
\hline Sujeito & + & $>$ & + & $>$ & + & $>$ & + & $>$ & + & $>$ & + & $>$ & + \\
\hline Objeto & - & $>$ & + & $>$ & + & $>$ & + & $>$ & + & $>$ & + & $>$ & + \\
\hline
\end{tabular}

Fonte: Dik (1997, p. 266)

A estrutura do predicado tem uma orientação básica, icônica (no exemplo 30, a ordem dos argumentos "representa" o movimento do livro), mas a atribuição da função sintática de objeto pode inverter esta perspectiva, justamente para dar proeminência a outro participante.

30. O homem (Agente/Sujeito) deu o livro (Paciente/Objeto) ao garoto (Recipiente)

31. O homem (Agente/Sujeito) deu ao garoto (Objeto/Recipiente) o livro (Paciente). (DIK, 1997, p. 253, tradução nossa5)

O autor esclarece que dois argumentos distintos raramente são marcados com o mesmo caso (por exemplo, segundo e terceiro argumentos marcados com caso Acusativo). Assim, os casos servem também para distinguir os argumentos.

Como visto nos exemplos 26 a 29, não somente argumentos, mas também satélites têm função semântica e podem ser marcados com morfologia de caso. Dik (1997) exemplifica este fato citando uma construção do latim com três satélites, todos marcados com caso Ablativo, mas cada um expressando uma função semântica distinta.

32. incredibili celeritate MAGNO SPATIO paucis diebus CONFECTO

'Depois de ter coberto uma grande distância [Ablativo Absoluto expressando circunstância] em poucos dias [Tempo] com inacreditável velocidade [Velocidade]' (DIK, 1997, p. 371, tradução nossa)

5 No original: "The man gave the book to the boy"; "The man gave the boy the book". 
Nossa análise das ocorrências de Ablativo coletadas do corpus digital é baseada principalmente nos pressupostos teóricos da Gramática Funcional de Dik. Ainda que com peso menor, utilizamos também pressupostos da Gramática Sistêmico-Funcional de Halliday (HALLIDAY; MATTHIESSEN, 2014).

Vimos, na seção anterior, que muitos usos de Ablativo são descritos nas gramáticas como complemento circunstancial. Na teoria de Halliday (1994), o mesmo elemento que exerce a função de circunstância na estrutura de transitividade (metafunção Experiencial) tem a função de adjunto no âmbito da metafunção Interpessoal. O elemento circunstancial pode expressar: extensão, localização, modo, causa, entre outros (HALLIDAY; MATTHIESSEN, 2014, p. 314). Uma de suas funções principais é localizar um evento no espaço e/ou no tempo.

Quadro 4. Circunstanciais de extensão e localização

\begin{tabular}{|l|l|l|}
\hline & Espacial & Temporal \\
\hline $\begin{array}{l}\text { Extensão } \\
\text { (inclui intervalo) }\end{array}$ & $\begin{array}{l}\text { Distância } \\
\text { (andar 7 milhas; parar a cada 10 jardas) }\end{array}$ & $\begin{array}{l}\text { Duração } \\
\text { (ficar 2 horas; pausar a cada 10 minutos) } \\
\text { Frequência } \\
\text { (bater três vezes) }\end{array}$ \\
\hline Localização & $\begin{array}{l}\text { Lugar } \\
\text { (trabalhar na cozinha) }\end{array}$ & $\begin{array}{l}\text { Tempo } \\
\text { (acordar às 6 horas) }\end{array}$ \\
\hline
\end{tabular}

Fonte: Halliday e Matthiessen (2014, p. 315, tradução nossa $\left.{ }^{6}\right)$

A categoria de Localização localiza o processo no espaço ou no tempo. A categoria de Extensão expressa o desenrolar de um processo no espaço ou no tempo, isto é, a distância no espaço ou a duração de tempo no qual o processo se desenvolve. Analisase, portanto, não somente a localização estática, mas a marcação de orientações como ponto de partida, trajeto e destino, seja no espaço ou nos seus análogos temporais.

Cabe, por fim, esclarecer a metodologia adotada no presente estudo. A análise a seguir se baseia em um corpus constituído por ocorrências de substantivo no caso Ablativo, coletadas em doze veículos de comunicação digitais (Agos, Massis Post, Vatican News, Hay Em News, Horizon, Aztag Daily, Diario Armenia, Arevelk, Asbarez, Ragmamoul, Azat Or, Hairenik Weekly) de nove países (Argentina, Armênia, Canadá, Chipre, Estados Unidos, Grécia, Líbano, Turquia e Vaticano), abrangendo um período de dez anos (2010-2020).

6 No original: "Walk (for) seven miles; stop every ten yards; work in the kitchen; stay (for) two hours; pause every ten minutes; knock three times; get up at six o'clock". 


\section{Análise dos usos do Ablativo no corpus}

As ocorrências coletadas no corpus digital mostram que o Ablativo pode exercer uma grande variedade de funções semânticas e sintáticas.

Comecemos nossa análise pela Sintaxe do Ablativo, mais especificamente pelo seu escopo. Do ponto de vista sintático, o Ablativo pode estabelecer:

(i) uma relação entre termos dentro do sintagma adjetival ou nominal, como em (33) e (34).

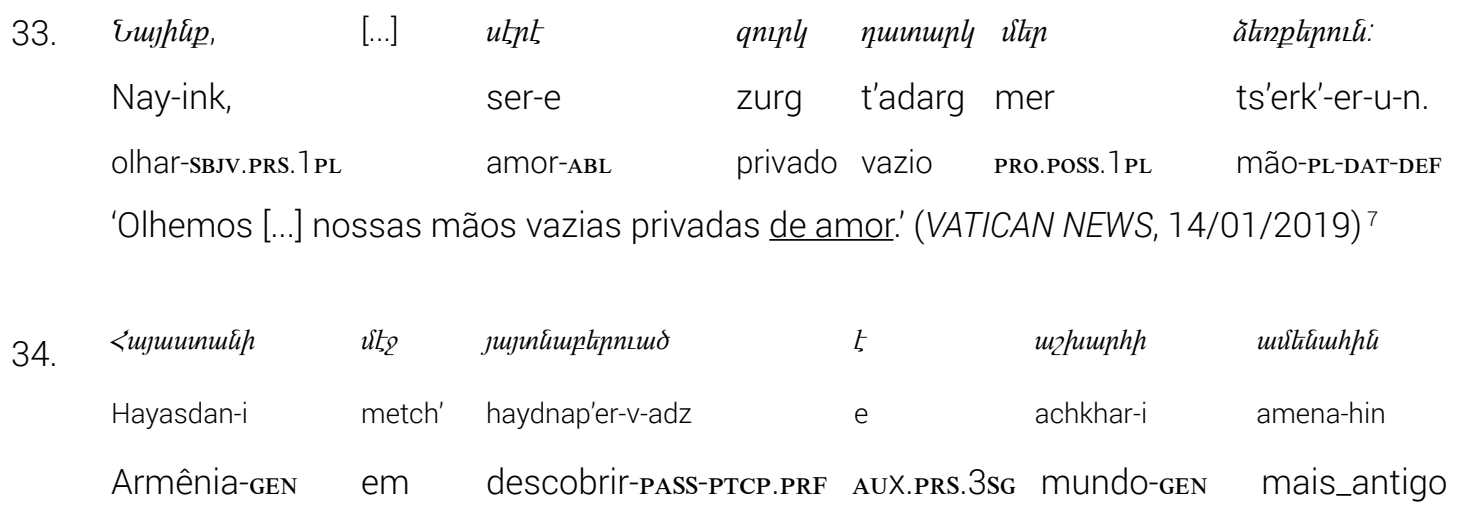

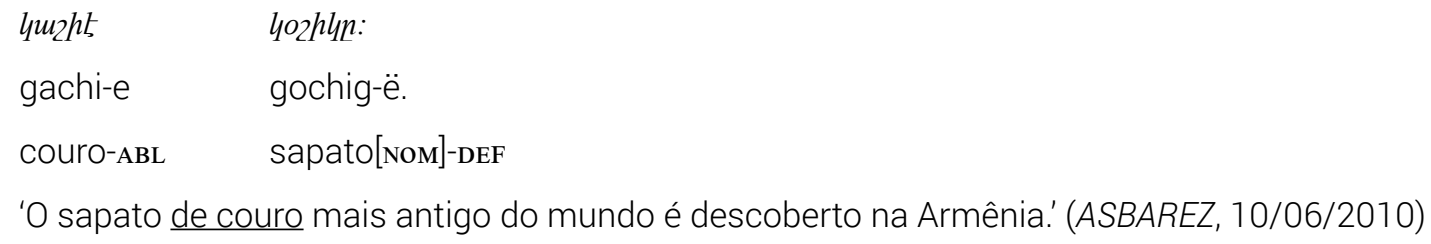

(ii) uma relação entre o verbo e seus argumentos internos, atuando dentro do sintagma verbal, como em (35), (36) e (37):

\begin{tabular}{|c|c|c|c|c|}
\hline ஓпиррһий & usup & {$[\ldots]$} & 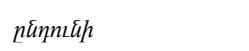 & $h n$ \\
\hline T'urk'ia-n & bedk' & $\overline{\mathrm{e}}$ & ënt'un-i & ir \\
\hline Turquia[NOM]-DEF & necessário & AUX.IND.PRS.3SG & admitir-SBJV.PRS.3SG & PRO.POSS.3sG \\
\hline
\end{tabular}

7 As ocorrências são identificadas com o nome do periódico digital de onde foram retiradas e data da matéria. 


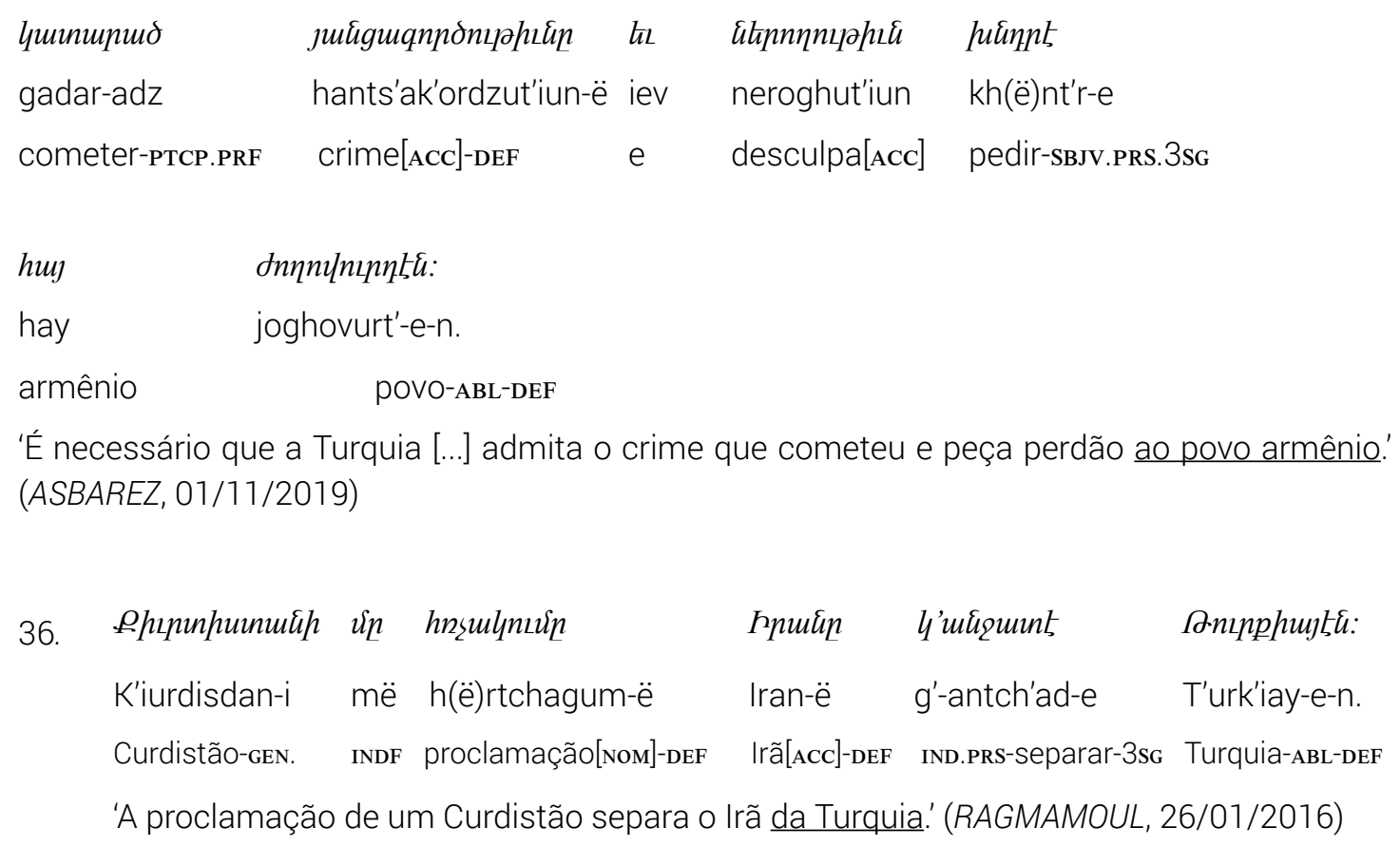

(iii) uma relação com a predicação como um todo, situando-a no tempo ou no espaço através de adjuntos circunstanciais, como em (38):

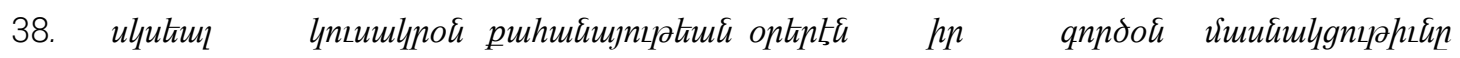
(ë)sg(ë)sial kusagron k'ahanayut'-ian or-er-e-n ir k'ordzon masnagts'ut'iun-ë inicial celibatário sacerdócio-GeN dia-PL-ABL-DEF PRo.Poss.3sg ativa participação[ACc]-DEF

\begin{tabular}{|c|c|c|c|c|c|c|}
\hline ptipurd & tn & Tuunphuppulquर् & Upnnh & 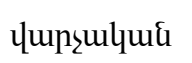 & 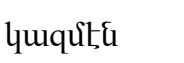 & Eitpu: \\
\hline p'er-adz & er & Badriark'agan & At'or-i & vartch'agan & gazm-e-n & ner \\
\hline trazer-PTCP.PRF & AUX.IMPERF.3sG & Patriarcal & Sé-Gen & administrativo & estrutura-ABL-DE & dent \\
\hline
\end{tabular}


'Desde os dias iniciais de seu sacerdócio celibatário, ele contribuiu com sua participação ativa na equipe administrativa da Sé Patriarcal.' (AGOS, 08/03/2019)

Assim, são diversas as funções sintáticas que o Ablativo pode exercer na sentença. No primeiro contexto, o elemento marcado com caso Ablativo pode corresponder a um complementador (como em 33) ou adjunto (como em 34), seja do adjetivo ou do substantivo. Em (ii), a morfologia de Ablativo marca o terceiro argumento, com função sintática de objeto do verbo (como em 35 e 36) ou de complemento oblíquo (como em 37).

Quando equivale a um elemento circunstancial, pode ter como escopo o sintagma verbal (exemplo 41) ou toda uma sentença (exemplos 39 e 40), exercendo as funções de adjunto adverbial de lugar, tempo e causa, como respectivamente ilustram os exemplos a seguir.

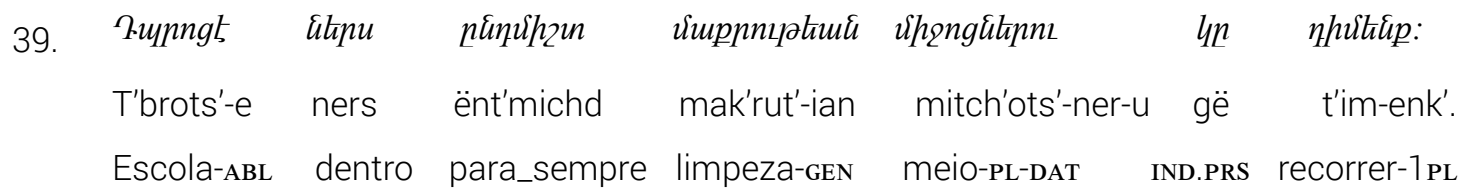

'Recorremos definitivamente aos meios de limpeza dentro da escola.' (AGOS, 11/03/2020)

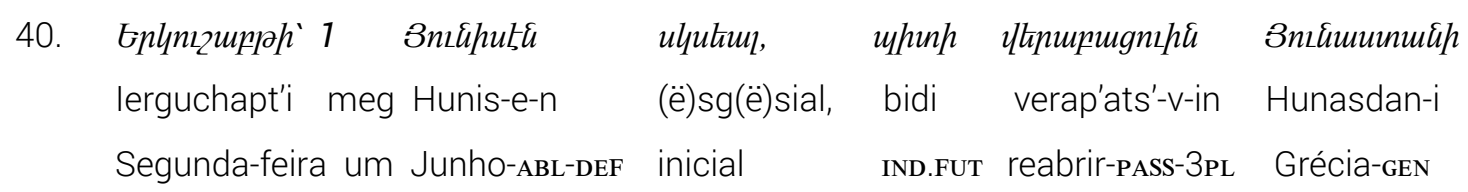

\begin{tabular}{|c|c|c|}
\hline quuһulyppupudiditinn & til & 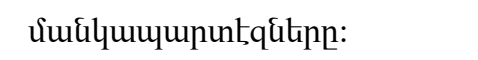 \\
\hline nakha-k'(ë)rt'aran-ner-ë & iev & mangabard'ez-ner-ë. \\
\hline pré-ginásio[NOM]-PL-DEF & e & jardim_da_infância[Nom]-PL-DEF \\
\hline
\end{tabular}

'A partir de segunda-feira, 1 de junho, as escolas gregas pré-ginasiais e jardim da infância abrirão.' (AZATOR, 25/05/2020)

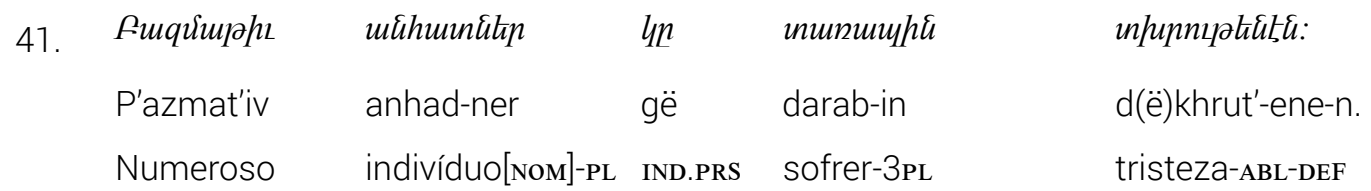

'Numerosos indivíduos sofrem de tristeza.' (VATICAN NEWS, 26/04/2020)

Enfatizamos que o elemento marcado com caso Ablativo pode constituir tanto um argumento (seja do nome, seja do verbo), quanto um elemento circunstancial, nãoobrigatório e dispensável, o chamado satélite ou adjunto. 
Passemos à Semântica do Ablativo. O traço semântico do elemento marcado pelo caso Ablativo apresenta grande variação, podendo corresponder a um substantivo [+concreto], [-animado], [+humano], ou [+abstrato]. Analisando a função semântica, constatamos que, além de Locativo e Tempo, o termo com morfologia de Ablativo pode corresponder a um Agente (como no exemplo 42), Origem (como nos exemplos 35, 36, 37 e 43) ou Referência (como em 44). Quando exerce a função de Referência, o substantivo no Ablativo é complementador do adjetivo predicativo, expressando comparação. Predominam no corpus as funções de Origem, Tempo e Locativo.

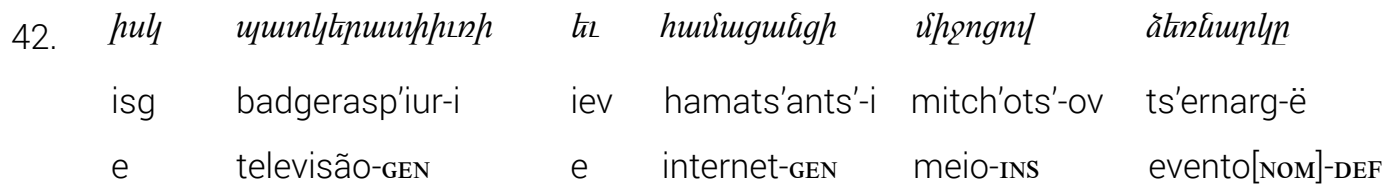

\begin{tabular}{|c|c|c|c|c|c|}
\hline whinh & mkuunıh & 145 & thnhnatints & thr & hппштппшодрйћn5: \\
\hline bidi & $\operatorname{desn}(\ddot{e})-v-i$ & hariur k'arasun-hink' & iergir-ner-e & iev & hoghadaradzk'-ner-e. \\
\hline ND.FUT & ver-PASS-3sg & cem quarenta-_e_cinco & país-PL-ABL & e & território-PL-ABL \\
\hline
\end{tabular}

'E o evento será visto por 145 países e territórios por meio da internet e televisão.' (MASSIS POST, 13/12/2018)

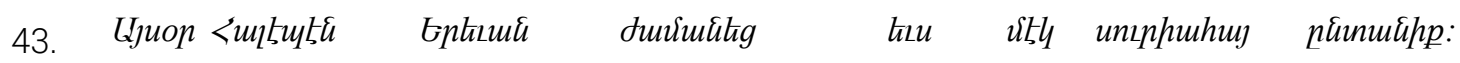
Aysor Haleb-e-n lerevan jamane-ts iev(ë)s meg suriahay ëndanik'. Hoje Alepo-ABL-DEF lerevan[Acc] chegar-IND.Aor.3sg mais um sírio-armênio família[Nom] 'Hoje chegou de Alepo a lerevan mais uma família sírio-armênia.' (AREVELK, 28/02/2017)

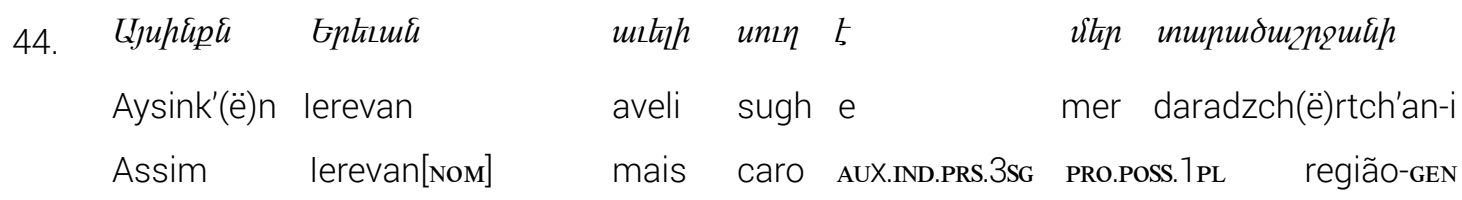

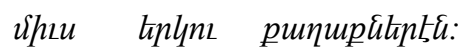
mius iergu k'aghak'-ner-e-n.
outro dois cidade-PL-ABL-DEF

Assim, lerevan é mais cara do que as outras duas cidades de nossa região.' (HAY EM NEWS, 21/01/2020)

'Quando correspondente a um elemento circunstancial, um satélite que localiza o estado de coisas no espaço (físico ou abstrato, como o espaço institucional do exemplo 46), uma das possibilidades é expressar uma localização estática, pontual; exemplos: 


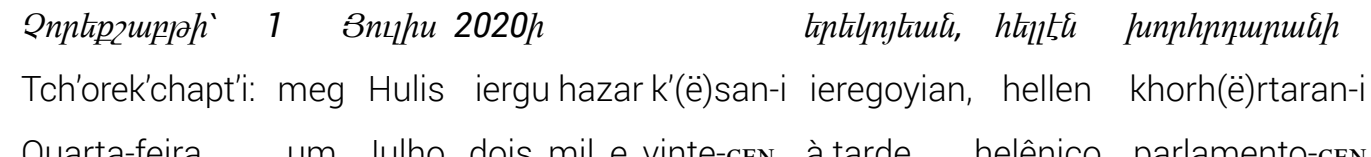

\begin{tabular}{|c|c|}
\hline Stınulnjmn & unuhbe् \\
\hline Dzeraguyd-i & s(ë)rah-e-n \\
\hline Senado-GEN & salão-ABL-DEF \\
\hline
\end{tabular}

'Na tarde de $4^{\text {a }}$ feira, em 1 de julho de 2020, no salão do Parlamento Helênico, [...]' (AZAT OR, 02/07/2020)

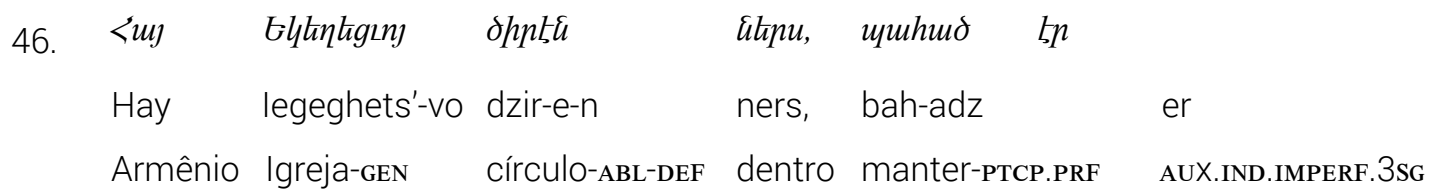

\begin{tabular}{|c|c|c|}
\hline Tпрuп & Upnnh & १һppn, \\
\hline Bolso & At'or-i & t’irk'-ë, \\
\hline Constantinopla & Sé-GEN & posição[ACC]-DEF \\
\hline
\end{tabular}

'Na esfera da Igreja Armênia, ele manteve a posição da Sé de Constantinopla, [...]' (AGOS, 08/03/2019)

A localização no tempo pode se dar não por uma expressão de tempo, mas por um evento que é tomado como ponto de referência temporal, sendo este marcado com Ablativo.

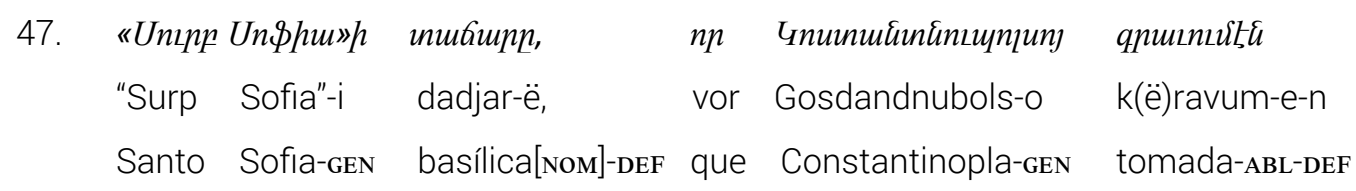

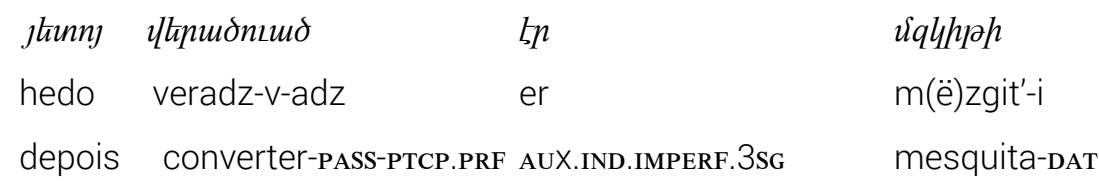

'A basílica de Santa Sofia, que foi convertida em mesquita depois da tomada de Constantinopla [...]' (AZAT OR, 12/07/2020)

Outra possibilidade é localizar o evento em termos de uma extensão, em que o elemento com morfologia de Ablativo marca o início de um trajeto ou percurso no espaço $(48,49$ e 50) ou no tempo (51). O movimento implicado pode ser abstrato, como em (50). 


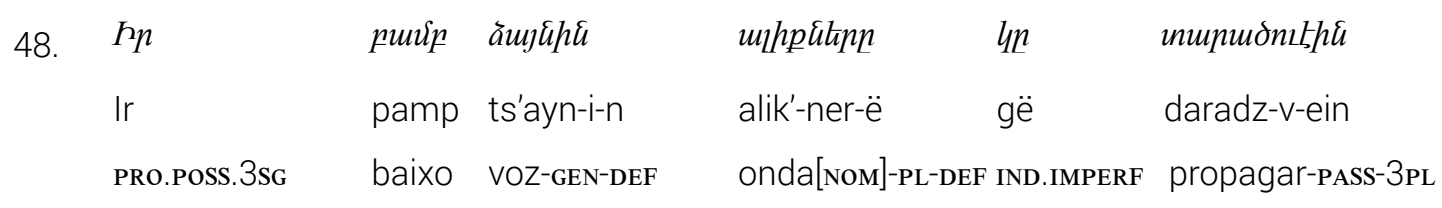

\begin{tabular}{|c|c|c|c|}
\hline пшишпшєһћ & vith & dumnt $\tilde{u}$ & vhrun \\
\hline t'asaran-i-n & meg & dzayr-e-n & mius-ë \\
\hline ala_de_aula-GEN-DEF & um & extremidade-ABL-DEF & outro[ACC]-DEF \\
\hline
\end{tabular}

'As ondas da sua voz baixa se propagavam de uma ponta a outra da sala de aula.'(HAIRENIK WEEKLY, 04/07/2020)

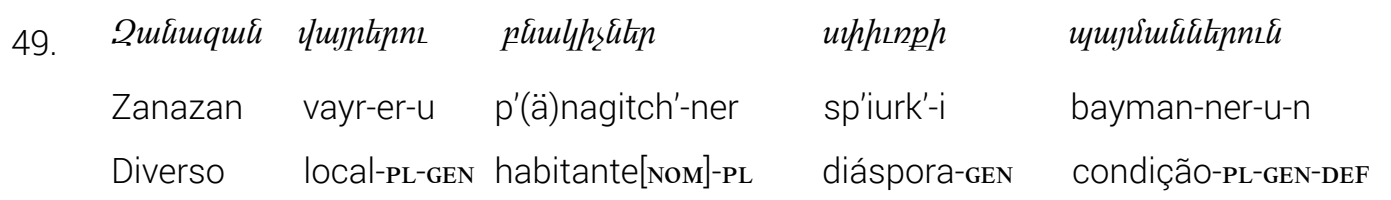

\begin{tabular}{|c|c|c|c|c|c|c|}
\hline 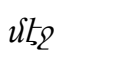 & styinknnitiny & $h$ & $u h$ & pknhe & hntikg & shzumиuluktnn, \\
\hline metch & megdeghvel-ov & i & $\mathrm{mi}$ & per-in & irents' & hichadag-ner-ë, \\
\hline em & reunir[INF] INS & PREP & um & trazer[IND.AOR]-3PL & PRO.POSS.3PL & lembrança-PL-DEF \\
\hline npnup & шщщ ше & & $n$ & ămน๖ย & әијрпцио & 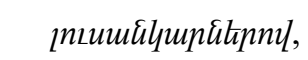 \\
\hline voronk & aba atch' & & u & ts'akh-e-n & t'ayt'-v-adz & usangar-ner-ov, \\
\hline PRO.REL.F & PL então direita[A & & e & esquerda-ABL-DEF obte & I-PASS-PTCP.PRF & fotografia-PL-INS \\
\hline
\end{tabular}

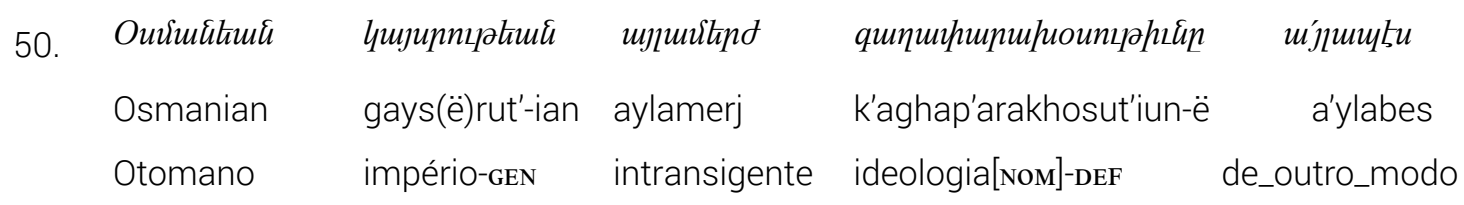

\begin{tabular}{|c|c|c|c|c|c|c|}
\hline $4 n$ & pumhungt & untsu & $i n k \eta$ & шпмимции & w2humht\& & ulukim \\
\hline gë & t'ap'ants'-e & amen & degh & arap'agan & achkhar-e-n & 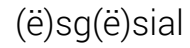 \\
\hline IND.PRS & atravessar-3sg & todo & lugar & árabe & mundo-ABL-DEF & inicial \\
\hline
\end{tabular}

\begin{tabular}{|c|c|c|}
\hline Shusktu & unkıน\{nkuर्u & knlhnithn \\
\hline mintch'ev & arevm(ë)dian & iergir-ner: \\
\hline até & ocidental & país[ACC $]$-PL \\
\hline
\end{tabular}


'A ideologia intransigente do Império Otomano, de outro modo, atravessa todo lugar: desde o mundo árabe até países ocidentais.' (AZAT OR, 12/07/2020)

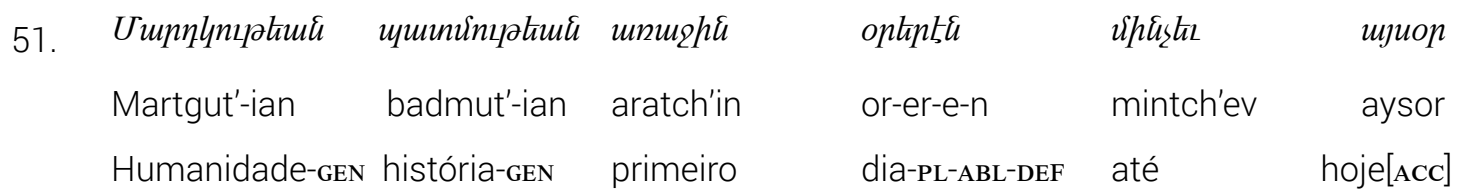

\begin{tabular}{|c|c|c|c|}
\hline hupüน & 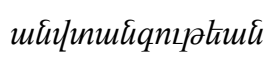 & lunhpultine & $\hbar \hat{U}$, \\
\hline ink'nin & anvdank'ut'-ian & garik'-ner-n & en, \\
\hline próprio & segurança-GEN & necessidade[NOM]-PL-DEF & AUX. IND.PRES.3PI \\
\hline
\end{tabular}

'Desde os primeiros dias da história da humanidade até hoje, estão as necessidades próprias de segurança [...].' (AZTAG DAILY, 23/12/2019)

Remetendo a uma extensão de tempo, pode tanto indicar o início de uma ação ou processo (como em 51, 52, 53 e 40), quanto o tempo que levará para uma ação ou processo ter início num tempo futuro (como em 54).

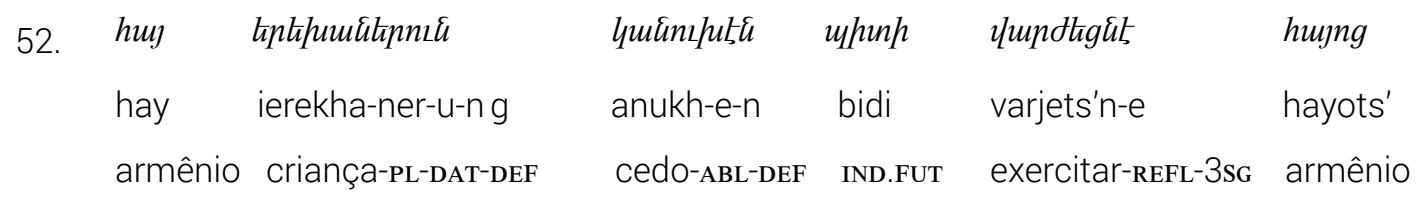

ujpnıptiup ununtipnı\&

ayp'up'en-i dar-er-u-n

abecedário-GEN letra-PL-ACC-DEF

'[...] se ensinará as letras do alfabeto armênio às crianças armênias desde tenra idade.' (AZAT OR, 7/10/2016)

\begin{tabular}{|c|c|c|c|c|c|}
\hline Титпримпршиций & 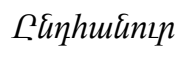 & Фпиишіпn & Uпршqши् & <ünn & uјu \\
\hline Badriark'agan & Ënt'hanur & P'okhanort' & S(ë)rp'azan & Hayr-ë & ays \\
\hline Patriarcal & Geral & Vigário & Santo & Padre[NOM]-DEF & D. \\
\hline
\end{tabular}

\begin{tabular}{|c|c|c|c|c|c|}
\hline unрhц & 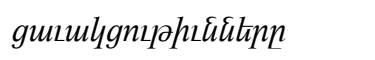 & whinh & 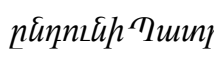 & 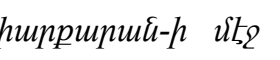 & ưर्दE on \\
\hline art'iv & ts'avagts'ut'iun-ner-ë & bidi & ënt'un-i & Badriark'aran-i & metch' amen or \\
\hline م & condolência[ACc] & IND.FUT & receber-3sg & Patriarcado-gEN & todo dia \\
\hline
\end{tabular}




\begin{tabular}{|c|c|c|c|}
\hline duvin & $10.005 \tilde{a}$ & whasktas & 16.00: \\
\hline jamë & das-e-n & mintch'ev & dasn(ë)vets. \\
\hline hora & deZ-ABL-DEF & até & dezesseis[Acc] \\
\hline
\end{tabular}

'Nesta ocasião, o Padre [celibatário], Vigário Geral Patriarcal, receberá as condolências no Patriarcado, todo dia, das 10:00 às 16:00 horas.' (AGOS 08/03/2019)

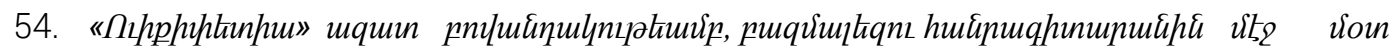
"Uik'ip'edia" azad p'ovant'agut'-iamp, p'azmalezu han(ë)rak'idaran-i-n metch' mod Wikipédia livre conteúdo-INs multilíngue enciclopédia-GeN-DEF em aproximadamente

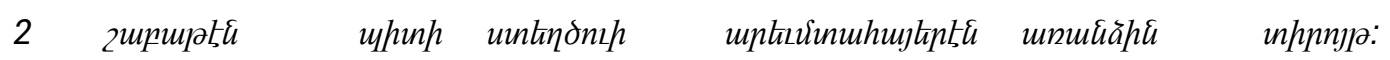
iergu chap'at'-e-n bidi (ë)sdeghdz-v-i arevm(ë)dahayeren arants'in diruyt'. dois semana-ABL-DEF IND.Fut criar-PASs-3sg armênio_ocidental separado domínio[Nom] 'Com conteúdo livre "Wikipedia", um domínio separado armênio ocidental será criado em aproximadamente duas semanas na enciclopédia multilíngue.' (DIARIO ARMENIA, 12/02/2019)

Quando estabelece uma relação entre termos, exerce a função de qualificador de um nome, designando uma propriedade. Por vezes, esta propriedade é pertencer a um grupo determinado, contexto em que o elemento no caso Ablativo indica o todo do qual se retirou uma parte (o que pode ser entendido em termos de um movimento fictício).

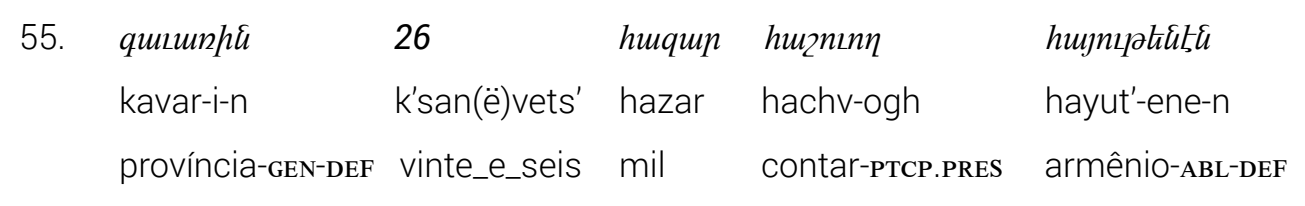

\begin{tabular}{|c|c|c|c|c|}
\hline ұпџпьшо & $\hbar \tilde{U}$ & 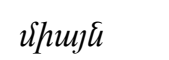 & 3 & hшqшир: \\
\hline $\mathrm{p}(\ddot{e}) \mathrm{rg}-\mathrm{v}-\mathrm{adz}$ & en & miayn & ierek' & hazar-ë. \\
\hline Salvar-PASS-PTCP.PRF & AUX. IND.PRES.3PL & somente & três & $\operatorname{mil}[$ NOM] $]$-DEF \\
\hline
\end{tabular}

\section{Considerações finais}

Com base em um corpus atual de armênio ocidental, procuramos, neste trabalho, analisar o caso Ablativo em contextos de uso mais amplos do que aqueles contemplados nas gramáticas, de modo a identificar suas funções semânticas e sintáticas, de uma perspectiva funcionalista. A hipótese inicial, de que tais usos poderiam ser explicados 
em termos da categoria conceptual de "origem", se confirma apenas parcialmente. É fato que muitas ocorrências podem ser assim analisadas. Isto inclui, por exemplo, a designação do material de composição de determinado objeto, do conjunto do qual algo ou alguém faz parte, o ponto de partida de um percurso no tempo ou no espaço, a causa de um processo, o Agente de uma ação, etc. Quando, porém, voltamos nossa atenção para instâncias que designam não a categoria de extensão, mas a de localização pontual especificamente no espaço, vemos que o sentido de "origem" não dá conta de explicar estes usos. Assim, os dados coletados apontam antes para a multifuncionalidade do caso Ablativo no armênio ocidental, tornando, por isso mesmo, difícil identificar um sentido comum a todos os empregos.

\section{REFERÊNCIAS}

AGOS, Turquia. Disponível em: http://www.agos.com.tr. Acesso em: 24 set. 2020.

AREVELK, Armênia. Disponível em: http://www.arevelk.am. Acesso em: 24 set. 2020.

ASBAREZ, Estados Unidos. Disponível em: http://asbarez.com/arm. Acesso em: 24 set. 2020.

AZAT OR, Grécia. Disponível em: http://azator.gr. Acesso em: 24 set. 2020.

AZTAG DAILY, Líbano. Disponível em: http://www.aztagdaily.com. Acesso em: 24 set. 2020.

BARDAKJIAN, K. B.; THOMSON, R. W. A Textbook of Modern Western Armenian. New York: Caravan Books, 1992.

CASTILHO, A. T. de. Nova Gramática do Português Brasileiro. São Paulo: Editora Contexto, 2010.

DIARIO ARMENIA, Argentina. Disponível em: http://www.diarioarmenia.org.ar. Acesso em: 24 set. 2020.

DIK, S. C. The Theory of Functional Grammar. Part 1: The Structure of the Clause. Berlin/ New York: Mouton de Gruyter, 1989/1997.

EKIZIAN, C. Sobre a gramática da língua armênia. 2. ed. São Paulo: Humanitas, 2004.

FEYDIT, F. Grammaire de la langue arménienne moderne: dialecte occidental. Venice: St. Lazare, 1935. 
GULIAN, K. Elementary Modern Armenian Grammar. New York: Frederic Ungar Publishing CO, 1902.

HAGOPIAN, G. Armenian for everyone: Western and Eastern Armenian in Parallel Lessons. New York: Caravan Books, 2005.

HAIRENIK WEEKLY, Estados Unidos. Disponível em: https://hairenikweekly.com. Acesso em: 24 set. 2020.

HALLIDAY, M A. K. An Introduction to Functional Grammar. 2. ed. London: Edward Arnold, 1994.

HALLIDAY, M. A. K.; MATTHIESSEN, C. M. I. M. Halliday's Introduction to functional grammar. 4. ed. London/New York: Routledge, 2014.

HAY EM NEWS, Chipre. Disponível em: https://hayemnews.com. Acesso em: 24 set. 2020.

KEROUZIAN, Y. O. Gramática do armênio moderno (dialeto ocidental). Inédito.

KOGIAN, Fr. S. L. Armenian grammar (West dialect). Vienna: Mechitharist Press, 1949.

MASSIS POST, Estados Unidos. Disponível em: http://massispost.com/am. Acesso em: 24 set. 2020.

RAGMAMOUL, Líbano. Disponível em: http://ragmamoul.net/hy/news. Acesso em: 24 set. 2020.

RIGGS, E. Grammar of the modern Armenian language as spoken in Constantinople and Asia Minor. 2. ed. Constantinople: A. B. Churchill, 1856.

SAKAYAN, D. Modern Western Armenian. Montreal: Arod Books, 2000.

SAKAYAN, D. Western Armenian for the English Speaking World. Yerevan: Yerevan State University Press, 2012.

VATICAN NEWS, Vaticano. Disponível em: https://www.vaticannews.va/hy.html. Acesso em: 24 set. 2020. 